\title{
Diapause, cold hardiness and flight ability of Cry1Ac-resistant and -susceptible strains of Helicoverpa armigera (Lepidoptera: Noctuidae)
}

\author{
Ge-Mei LIANG ${ }^{1}$, Kong-Ming WU $^{1 *}$, Brian RECTOR ${ }^{2}$ and Yu-YuAn GUO ${ }^{1}$
}

\begin{abstract}
${ }^{1}$ State Key Laboratory for Biology of Plant Diseases and Insect Pests, Institute of Plant Protection, Chinese Academy of Agricultu ral Sciences, No. 2 West Yuanmingyuan Road, Beijing, 100094, China; e-mail: gmliang@ippcaas.cn

${ }^{2}$ European Biological Control Laboratory, United States Department of Agriculture, Montpellier, France
\end{abstract}

Key words. Noctuidae, Helicoverpa armigera, Bt resistance, resistance management, fitness costs, transgenic crops

\begin{abstract}
The diapause inducement condition, cold hardiness, and flight ability in Cry1Ac-resistant (BtR) and Cry1Ac-susceptible (96S) strains of Helicoverpa armigera (Hübner) were compared in the laboratory. The BtR strain was derived from the 96S strain and shows 1375-fold resistance to the Cry1Ac toxin after having been selected for 52 generations. Compared with the $96 \mathrm{~S}$ strain, the Bt-resistant strain was more likely to go into diapause under a short-photoperiod environment. At 11L : 13D, 12L : 12D and 13L : $11 \mathrm{D}$ photoperiods, the percentages of BtR insects entering diapause were $72.7 \%, 82.9 \%$ and $68.7 \%$, respectively, which were significantly higher than those in the $96 \mathrm{~S}$ strain $(58.6 \%, 67.4 \%$ and $46.3 \%$, respectively) under the same conditions. The supercooling points (SCP) and freezing points (FP) were not significantly different between the BtR and $96 \mathrm{~S}$ strains. The $\mathrm{LT}_{50}(50 \%$ lethal time) and $\mathrm{LT}_{90}\left(90 \%\right.$ lethal time) of BtR pupae were also not significantly different from those of the $96 \mathrm{~S}$ strain at $-15^{\circ} \mathrm{C}$. The moths from both strains had similar flight ability when their larvae were fed with nontoxic control diet. However, the total flight distance of these BtR moths was $56.2 \mathrm{~km}$ whose larvae fed on normal diet, which was more than twice as much as for those feeding on Bt diet $(26.2 \mathrm{~km})$. Flight duration for these BtR moths was longer after feeding on normal diet $(11.6 \mathrm{~h})$ than after feeding on Bt diet $(7.3 \mathrm{~h})$.
\end{abstract}

\section{INTRODUCTION}

Helicoverpa armigera (Hübner) is one of the most serious pests of cotton, maize, wheat, sorghum and many other crops in the old world (Luttrell et al., 1994; Guo, 1997) and its high field-resistance to chemical insecticides is a major threat to cotton production in many countries (Forrester et al., 1993; Wu et al., 1997a). Currently, Bacillus thuringiensis Berliner transgenic cotton (Bt cotton) engineered to express a $\delta$-endotoxin from $\mathrm{Bt}$ has become a major means for control of this pest in China, India and Australia (Shelton et al., 2002; Wu \& Guo, 2005).

One of the main concerns associated with the widespread adoption of $\mathrm{Bt}$ cotton is the evolution of $H$. armigera resistance to Cry1Ac. In fact, the capacity of $H$. armigera for resistance development to Cry1 Ac has been demonstrated in several laboratory-selected strains from India, China and Australia (Kranthi et al., 2000; Liang et al., 2000; Akhurst et al., 2003). The "high-dose/refuge" strategy, has been in practice to delay the development of field resistance to Bt crops by insect pests (Bates et al., 2005). In this strategy, the Bt crop was designed to produce enough toxin to kill nearly all heterozygous insects, while a nearby area of non-Bt plants would allow susceptible insects to survive so that the moths from both populations could mate, thus diluting the resistance gene in the offspring (Liu \& Tabashnik, 1997; Peck et al., 1999; Shelton et al., 2000; Tang et al., 2001; Caprio et al., 2004; Tabashnik et al., 2004).
Current theory dictates that the evolution of resistance to $\mathrm{Bt}$ involves the interaction of many genetic and biological factors (Tabashnik, 1994; Gahan et al., 2005; Tabashnik et al., 2005), in which fitness costs are incurred that are the result of negative pleiotropic effects of genes that confer resistance and result in the fitness of resistant individuals being lower than that of susceptible individuals in the absence of toxin. These effects play an important role in the development of resistance in natural environments (Groeters et al., 1994). In general, fitness costs associated with Bt-resistance are well-documented and can substantially affect survival and development (Tang et al., 1997; Ramachandran et al., 1998; Akhurst et al., 2003; Tabashnik et al., 2003; Tabashnik \& Carrière, 2004), pupation rate and pupal weight (Huang et al., 2005), diapause (Carrière et al., 2001) and mating success (Groeters et al., 1994; Alyokhin \& Ferro, 1999; Higginson et al., 2005). There have also been two reports on reduced fitness in Bt-resistant $H$. armigera on transgenic cotton affecting survival, development and diapause (Bird $\&$ Akhurst, 2004, 2005). However, other fitness differences between the Bt-resistant and wild-type $H$. armigera have been unclear until now. Here we report research results on differences in cold hardiness, diapause and flight ability between CrylAc-resistant and wild-type $H$. armigera.

\footnotetext{
* Corresponding author; e-mail: kmwu@ippcaas.cn
} 


\section{MATERIAL AND METHODS}

\section{Insect cultures and bioassays}

A field population of $H$. armigera was collected from Xinxiang County, in Henan Province, China in 1996 and cultured on artificial diets in the laboratory (the artificial diets were mixed as described by Liang et al., 1999). As a control treatment (96S), the original field population was reared on artificial diet without exposure to any chemical insecticide or Bt toxin. For selecting a resistant strain, increasing amounts of Cry1Ac protoxin (extracted from B. thuringiensis HD73, cordially provided by the Biotechnology Group in Institute of Plant Protection, Chinese Academy of Agricultural Sciences) were added into the artificial diet with a selective pressure at which about twenty percent of the selected neonates could develop successfully to pupation (Liang et al., 2000). The Cry1Ac-resistant $H$. armigera strain (BtR) in this study has been selected with CrylAc protoxin for 52 generations. In order to minimize genetic differences other than the resistance character between the $96 \mathrm{~S}$ and BtR strain, the selected strain was backcrossed with $96 \mathrm{~S}$ strain in both the 27th and 49th generations. After these backcrosses, the offspring were reselected with a lower concentration Bt-diet followed by continually increasing doses of Cry1Ac in the artifical diet generation by generation. The insect cultures and bioassays in this study were maintained at $27 \pm$ $2{ }^{\circ} \mathrm{C}, 75 \pm 10 \% \mathrm{RH}$ and a photoperiod of $14 \mathrm{~L}: 10 \mathrm{D}$, unless otherwise noted.

In bioassays different amounts of CrylAc protein (MVP endotoxin protein, Mycogen, San Diego, CA) were homogeneously mixed with the artificial diet. After the artificial diet solidified, $0.3-0.4 \mathrm{~g}$ portions were transferred to 24 -well trays. One $H$. armigera neonate was transferred into each well and mortality of the larvae was recorded after 7 days. A total of 12 neonates were used for each concentration of $\mathrm{Bt}$ protein in the diet $(2700,900,300,100,33.33 \mu \mathrm{g} / \mathrm{g}$ for resistant strain; 3.7 , $1.23,0.41,0.14,0.05 \mu \mathrm{g} / \mathrm{g}$ for susceptible strain) and for the control treatment (with only distilled water added). Each treatment had four replicates.

\section{Diapause inducement condition and critical photoperiod test}

$H$. armigera neonates were placed on the artificial diet in glass-tubes and maintained in growth chambers at $22^{\circ} \mathrm{C}$ with photoperiods of either $11 \mathrm{~L}: 13 \mathrm{D}, 12 \mathrm{~L}: 12 \mathrm{D}, 13 \mathrm{~L}: 11 \mathrm{D}$ or $14 \mathrm{~L}$ : $10 \mathrm{D}$ until pupation. The diapause and non-diapause pupae were distinguished by observing the movement and eventual disappearance of the pigmented eyespots during $H$. armigera pupal development (Phillips \& Newsom, 1966). Two hundred neonates were tested for each treatment. Each experiment was repeated three times. After seven days, diapause and nondiapause pupae were recorded and the data were compared to the normal time for diapause for this species (Wu \& Guo, 1995). The percentages of diapause pupae under different photoperiods between the susceptible and resistant $H$. armigera strains were calculated.

\section{The cold-hardiness test}

Pupal temperature gradually decreases along with the temperature in the freezer until the pupal temperature reaches the supercooling point (SCP), when the body fluids begin to freeze. At this time, the pupal temperature rapidly increases due to the heat released from the freezing pupae. Pupal temperature increases and then decreases again, forming a small peak, and the peak temperature is determined to be the freezing point (FP).

The SCPs and FPs of diapause and non-diapause pupae in the BtR and 96S strains were measured as described by Zhu et al. (1994). In brief, a heat-sensitive probe was fixed to a pupa and the pupa was placed in a low-temperature refrigerator $\left(0^{\circ} \mathrm{C}\right)$ with the temperature reduced by $0.1^{\circ} \mathrm{C} / \mathrm{min}$. Pupal temperature was automatically monitored using a computer. Seven days after the larvae pupated, the largest and healthiest individuals of diapause and non-diapause pupae from the BtR and $96 \mathrm{~S}$ strain were selected for testing. A total of 15 diapause or non-diapause pupae were tested each time. The experiment was repeated three times.

The survivability of diapause and non-diapause pupae between the BtR and 96S strains was determined as described by $\mathrm{Wu}$ et al. (1997b). The pupae of both strains were kept for 5 $\mathrm{d}$ at $4^{\circ} \mathrm{C}$, and then were embedded in a container under $6-8 \mathrm{~cm}$ of soil at $-15^{\circ} \mathrm{C}$. The diapause and non-diapause pupae were taken out from the freezer at different time intervals, maintained under laboratory conditions $\left(25^{\circ} \mathrm{C}\right)$, and pupal survival was recorded after $72 \mathrm{~h}$. Twelve diapause pupae each were taken out after 3, 4, 5, 6, 8, and $12 \mathrm{~h}$ had elapsed. Fifty non-diapause pupae each were taken out after 4, 6, 8, 12, 24, 48, and $72 \mathrm{~h}$ had elapsed. Each experiment was repeated three times.

\section{Flight ability test}

The test apparatus was a 32-channel computer-monitored flight-mill system made by the Institute of Plant Protection, Chinese Academy of Agricultural Sciences, Beijing. The 32 flight mills, positioned on wire shelves, were operated in a controlled room. The system automatically recorded the main flight parameters of 32 adults, including flight speed, duration and distance. Approximately $2 \mathrm{~h}$ before the onset of testing, tethers were attached to individual moths that were slightly anesthetized using ether, on the dorsal surface of the thorax, from which scales had been removed of. The moths were attached by placing a drop of 502 Glue (a cyanoacrylate glue, Youxing Adhesive Co., Guangdong, China) on the small loop of the tether electrical wire (the moth tether was fabricated with a 20 -mm length of 0.64-mm-diameter wire and a 13-mm length of plastic insulation that had been removed from electrical wire of $1 \mathrm{~mm}$ diameter) and holding the wire loop and glue in contact with the dorsal surface of the anesthetized moth's thorax with the aid of forceps and a magnifying glass. After drying the adhered portion, the anesthetized adult was put into a test tube. After recovery from anesthesia, the adult was allowed to fly. At the time of moth attachment to the flight mill, the shape of the tether wire was modified by bending as necessary to position the moth in a horizontal flight attitude (Beerwinkle et al., 1995). The flight ability of 15 males and 15 females reared on Bt-diet (the dose of Cryl Ac was $14 \mu \mathrm{g} / \mathrm{g}$ ) or normal diet in the $96 \mathrm{~S}$ and BtR strains was measured in the laboratory $\left(23^{\circ} \mathrm{C}, 60 \% \mathrm{RH}\right.$ and photoperiod of $0 \mathrm{~L}: 24 \mathrm{D})$. The effects of strain, diet and sex on flight potential in $24 \mathrm{~h}$ of unmated 1-d-old moths were recorded. Each experiment was repeated three times.

\section{Data analysis}

The $50 \%$-lethal concentration $\left(\mathrm{LC}_{50}\right)$ values were calculated by probit regression using POLO Software (Russell et al., 1977). Samples for which the $95 \%$ confidence intervals did not overlap were considered to be significantly different. The resistance ratio of the $\mathrm{BtR}$ strain was expressed as the $\mathrm{LC}_{50}$ of the resistant strain divided by the $\mathrm{LC}_{50}$ of the susceptible strain.

Survival of $H$. armigera at low temperature $\left(-15^{\circ} \mathrm{C}\right)$ was analyzed by time-mortality regressions using the probit analysis (POLO, Russell et al., 1977) as described by Eger et al. (1982). A two-sample $t$-test procedure for comparing the percentage of diapause pupae between the two strains at each photoperiod was conducted (SAS Institute, 1996). When $p<0.05$ the results were considered to be significant. The percentage of diapause pupae, supercooling points, freezing points, flight distance, flight speed and flight time in the two strains were analyzed by two-way 


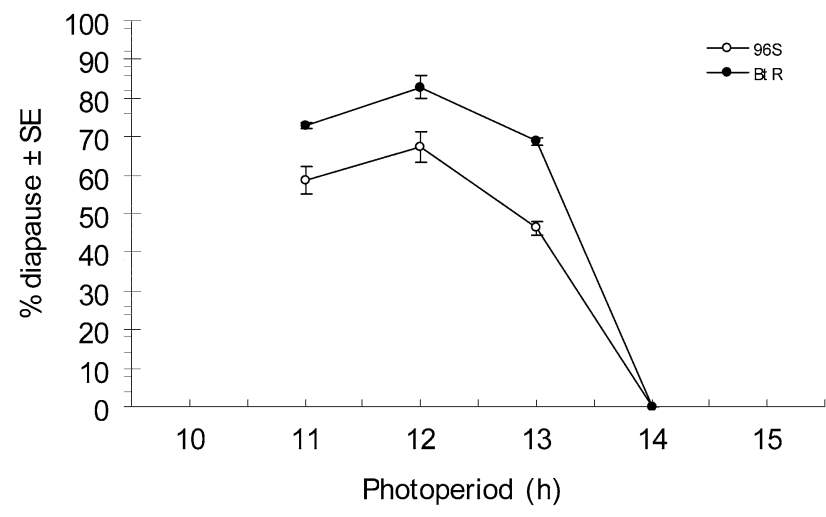

Fig. 1. The critical photoperiods of Bt susceptible and resistant strains of Helicoverpa armigera.

analysis of variance (ANOVA) with means separated using the least significant difference test (LSD) (SAS Institute, 1996).

\section{RESULTS}

\section{Resistance ratio of BtR strain}

The $\mathrm{LC}_{50}$ values for the $96 \mathrm{~S}$ strain and the BtR strain were $0.3 \mu \mathrm{g} / \mathrm{g}(95 \%$ confidence interval $=0.2-0.5)$ and $412.5 \mu \mathrm{g} / \mathrm{g}(95 \%$ confidence interval $=114.1-1420.7)$, respectively. Thus the relative resistance ratio of the BtR strain was 1375 -fold that of the $96 \mathrm{~S}$ strain.

\section{Diapause inducement condition}

The mean percentage of diapause pupae in the $96 \mathrm{~S}$ strain under a $12 \mathrm{~L}: 12 \mathrm{D}$ h photoperiod was $67.4 \pm 3.9 \%$, which was significantly higher than under 11L : 13D $(58.6 \pm 3.4 \%), 13 \mathrm{~L}: 11 \mathrm{D}(46.3 \pm 1.7 \%)$, or $14 \mathrm{~L}: 10 \mathrm{D}$ $(0 \%)$ photoperiods $(F=128.87 ;$ df $=3,8 ; P=0.0001)$ (Fig. 1). The pupal diapause rates were not significantly different between the treatments of 11L : 13D and 13L : $11 \mathrm{D}$ photoperiods. No diapause pupae were found when $H$. armigera were under the photoperiod of $14 \mathrm{~L}: 10 \mathrm{D}$. Similar results were obtained for the BtR strain. The percentage of diapause pupae in the BtR strain under a $12 \mathrm{~L}$ : $12 \mathrm{D}$ photoperiod was $82.9 \pm 3.0 \%$ which was significantly higher than under $11 \mathrm{~L}: 13 \mathrm{D}(72.7 \pm 0.8 \%), 13 \mathrm{~L}$ : $11 \mathrm{D}(68.7 \pm 1.1 \%)$, or $14 \mathrm{~L}: 10 \mathrm{D}(0 \%)$ photoperiods $(F=$ 413.11; df $=3,8 ; P=0.0001$ ) (Fig. 1). The percentage of diapause under the $11 \mathrm{~L}: 13 \mathrm{D}$ photoperiod in the BtR strain was significantly higher than that in the $96 \mathrm{~S}$ strain ( $t=4.01, P=0.036)$, which was also the case for the $12 \mathrm{~L}$ $: 12 \mathrm{D}$ photoperiod $(t=3.01, P=0.040)$ and the $13 \mathrm{~L}$ : $11 \mathrm{D}$ photoperiod $(t=10.84, P=0.0004)$. There were no differences at $14 \mathrm{~L}: 10 \mathrm{D}$ photoperiod between the two strains, as no diapause pupae were found in either strain.
TABLE 1. The comparison of supercooling points and freezing points of Helicoverpa armigera between diapause and nondiapause pupae of Bt-resistant and susceptible strains.

\begin{tabular}{cccc}
\hline Strain & Pupal diapause status & Mean SCP $\pm \mathrm{SE}^{*}$ & $\mathrm{Mean} \mathrm{FP} \pm \mathrm{SE}^{*}$ \\
\hline \multirow{2}{*}{$\mathrm{BtR}$} & Diapause pupae & $-19.1 \pm 0.7$ & $-7.4 \pm 1.7$ \\
& Non-diapause pupae & $-18.7 \pm 1.2$ & $-6.7 \pm 1.8$ \\
\multirow{2}{*}{$96 \mathrm{~S}$} & Diapause pupae & $-19.1 \pm 0.2$ & $-7.3 \pm 2.0$ \\
& Non-diapause pupae & $-18.3 \pm 1.6$ & $-6.2 \pm 2.3$ \\
\hline
\end{tabular}

*SCP is the supercooling point. FP is the freezing point.

\section{Cold hardiness of $\boldsymbol{H}$. armigera}

SCPs were not different between diapause and nondiapause pupae within either the BtR strain $(F=0.45$; df $=1,8 ; P=0.7219)$ or the $96 \mathrm{~S}$ strain $(F=2.01 ; \mathrm{df}=1,8 ; P$ $=0.1648)$ (Table 1$)$. The differences of FPs were also not significant between the diapause and non-diapause pupae in either the BtR $(F=0.66 ; \mathrm{df}=1,8 ; P=0.5819)$ or $96 \mathrm{~S}$ $(F=2.20 ; \mathrm{df}=1,8 ; P=0.1473)$ strain. When comparing the BtR strain to the $96 \mathrm{~S}$ strain, there were no significant differences in SCPs or FPs in the diapause $(F=0.73$; df $=$ $3,8 ; P=0.3958)$ or non-diapause $(F=0.40 ; \mathrm{df}=3,8 ; P=$ $0.5275)$ pupae. However, the diapause pupae had stronger cold hardiness than the non-diapause pupae within both the BtR and 96S strains. The combined data for SCP of diapause pupae from both strains was $-19.1^{\circ} \mathrm{C}$ which was significantly lower than the combined SCP of nondiapause pupae $\left(-18.5^{\circ} \mathrm{C}\right)(F=6.02 ;$ df $=3,8 ; P=$ $0.0165)$. There also was a significant difference between combined data for freezing points of diapause pupae $\left(-7.4^{\circ} \mathrm{C}\right)$ and those of non-diapause pupae $\left(-6.4^{\circ} \mathrm{C}\right)(F=$ $4.23 ; \mathrm{df}=3,8 ; P=0.0434)$.

The survival times at $-15^{\circ} \mathrm{C}$ of diapause or nondiapause $H$. armigera pupae were not significantly different between the BtR and $96 \mathrm{~S}$ strains, as the $95 \% \mathrm{CI}$ of $\mathrm{LT}_{50}$ values in these two strains overlapped (Table 2). The $\mathrm{LT}_{90}$ values between the diapause pupae and nondiapause pupae in both the BtR (95\% CI: 11.2-46.7 vs. 7.1-11.3) and 96S (11.6-32.5 vs. 6.4-11.8) strains were marginally significant based on slight overlapping of CI.

\section{Flight ability}

The larvae of the 96S strain that fed on Bt diet all died before pupation. Most of BtR strain larvae feeding on $\mathrm{Bt}$ diet completed their life cycle and the emerged moths could fly naturally but their flight ability was weaker than moths reared on normal diet (Table 3 ). The moths of the BtR strain reared on normal diet had similar flight ability to those of the $96 \mathrm{~S}$ strain moths that were also reared on normal diet. The BtR $H$. armigera reared on normal diet

TABLE 2. Survival of diapause and non-diapause pupae of Helicoverpa armigera at $-15^{\circ} \mathrm{C}$ between the Bt-resistant and susceptible strains.

\begin{tabular}{ccccccc}
\hline Strain & Diapause $/$ non-diapause & Slope $\pm \mathrm{SE}$ & $\mathrm{LT}_{50}(\mathrm{~h})$ & $95 \% \mathrm{CI}^{*}$ & $\mathrm{LT}_{90}(\mathrm{~h})$ & $95 \% \mathrm{CI}^{*}$ \\
\hline $96 \mathrm{~S}$ & Diapause & $3.2 \pm 0.6$ & 6.7 & $4.0-10.6$ & 16.8 & $11.2-46.7$ \\
BtR & Diapause & $3.4 \pm 0.8$ & 6.7 & $4.8-9.3$ & 16.0 & $11.6-32.5$ \\
$96 \mathrm{~S}$ & Non-diapause & $9.9 \pm 2.2$ & 6.1 & $5.2-7.7$ & 8.3 & $7.1-11.3$ \\
BtR & Non-diapause & $6.5 \pm 1.5$ & 4.9 & $3.9-6.2$ & 7.7 & $6.4-11.8$ \\
\hline
\end{tabular}

*CI is the confidence interval. 
TABLE 3. Flight ability of Helicoverpa armigera adults in different strains reared on different diets.

\begin{tabular}{lcc}
\hline Strain / Diet / Gender & $\begin{array}{c}\text { Mean total flight } \\
\text { distance } \pm \text { SE }(\mathrm{km})\end{array}$ & $\begin{array}{c}\text { Mean total flight } \\
\text { time } \pm \text { SE }(\mathrm{h})\end{array}$ \\
\hline 96S, Normal diet, Female & $63.6 \pm 16.0$ & $9.4 \pm 2.8$ \\
96S, Normal diet, Male & $50.7 \pm 11.5$ & $9.3 \pm 1.8$ \\
BtR, Normal diet, Female & $62.3 \pm 14.0$ & $12.6 \pm 2.0$ \\
BtR, Normal diet, Male & $48.7 \pm 8.9$ & $10.4 \pm 1.9$ \\
BtR, Bt diet, Female & $34.0 \pm 5.9$ & $9.6 \pm 1.7$ \\
BtR, Bt diet, Male & $21.0 \pm 9.7$ & $5.7 \pm 2.7$ \\
\hline
\end{tabular}

had significantly higher flight ability than those reared on Bt diet. The total flight distance of these BtR moths was $56.2 \pm 11.5 \mathrm{~km}$ for larvae fed on normal diet, which was more than twice as far than those feeding on Bt diet $(26.2$ $\pm 6.4 \mathrm{~km})$ and this difference was significant $(F=4.62 ; \mathrm{df}$ $=1,10 ; P=0.0408)$. Flight duration for these BtR moths after feeding on normal diet was also significantly longer $(11.6 \pm 2.0 \mathrm{~h})$ than those fed on Bt diet $(7.3 \pm 1.6 \mathrm{~h})(F=$ 5.65; df $=1,10 ; P=0.0284)$.

The flight distances and flight times of females were higher than for males in both the $96 \mathrm{~S}$ and BtR strains after the larvae fed on normal diet $(F=2.46$; df $=5,12 ; P$ $=0.1252)$. A similar result was also observed in the BtR strain after their larvae were fed with Bt diet $(F=0.61 ; \mathrm{df}$ $=5,12 ; P=0.4400)$, however none of these differences were significant. The differences of flight distance $(F=$ 1.44; df $=5,12 ; P=0.2329)$ and flight time $(F=1.13$; df $=5,12 ; P=0.3617)$ in strain $\times$ diet $\times$ gender interaction were not significant.

\section{DISCUSSION}

H. armigera generally has four generations on cotton in northern China. The fourth generation larvae undergo diapause under a short photoperiod, overwintering as diapause pupae. The pupation percentage and the cold hardiness of pupae directly affect the size of populations in the coming year (Wu et al., 1997b). The research reported here shows that compared with a CrylAc-susceptible strain, a CrylAc-resistant strain had a higher percentage of diapause pupation at the same photoperiod, which could affect subsequent years' populations (in terms of both population genetics and population size). Similar results have been reported in the literature. Carrière \& Roff (1995) demonstrated that insecticide-induced mortality could produce evolutionary change in diapause propensity of insects. In contrast, $\mathrm{Hu}$ et al. (1999) reported that the pupae of $H$. armigera with high levels of fenvalerate resistance had a lower diapause rate and reduced winter hardiness compared to pupae with lower levels of fenvalerate resistance. Bird \& Akhurst (2004) found the proportion of larvae that pupated under diapausing conditions was similar for Cry 1A-resistant and -susceptible populations of $H$. armigera.

The $\mathrm{LT}_{50}$, SCPs and FPs of the BtR strain were not significantly different from those of the $96 \mathrm{~S}$ strain. However, the $\mathrm{LT}_{90}$ of diapause pupae at $-15^{\circ} \mathrm{C}$ was marginally significantly higher than that of non-diapause pupae and the SCP and FP of diapause pupae were also significantly lower than those of non-diapause pupae. In other words, the diapause pupae were more cold-hardy than the non-diapause pupae. Because the percentage of diapause in the BtR strain was higher than in the $96 \mathrm{~S}$ strain under the same conditions, the BtR strain may ultimately have more endurance in a cold environment. In contrast, Carrière et al. (2001) investigated overwintering costs in pink bollworm, Pectinophora gosypiella (Saunders) strains with different degrees of resistance to $\mathrm{Bt}$ cotton and found that emergence from diapause in the spring was $71 \%$ lower in three highly resistant strains than in two heterogeneous strains from which the resistant strains were derived. Their data also underestimate the overwintering cost because the frequency of the resistance allele was relatively high in the heterogeneous strains. Our experiments were conducted in the laboratory, not in the field, and the survival time of pupae were determined at $-15^{\circ} \mathrm{C}$. Field conditions are more complex, with the soil temperature fluctuating regularly and many other biotic and abiotic factors affecting pupal survival. A comparison of pupal survival in the field between BtR and 96S strains should provide more insight into this phenomenon.

There were no significant differences in either flight distance or time between the $96 \mathrm{~S}$ and BtR strains (Table 3). However, the BtR individuals reared on Bt diet were not as robust as those reared on normal diet, as shown by their reduced flight. In addition, the pupae and emerged moths reared on $\mathrm{Bt}$ diet (the mean weights of these pupae and moths were $289.2 \mathrm{mg}$ and $188.1 \mathrm{mg}$, respectively) were significantly smaller than pupae and moths reared on normal diet, whose mean weights of were $318.8 \mathrm{mg}(F$ $=20.26 ; \mathrm{df}=1,4 ; P=0.0108)$ and $197.7 \mathrm{mg}(F=9.40 ; \mathrm{df}$ $=1,4 ; P=0.0374)$, respectively.

The BtR strain was highly resistant to CrylAc in artificial diets, BtR larvae survived for a longer time on Bt cotton, and more BtR larvae developed to the 5th instar on Bt cotton, whereas susceptible (96S) larvae had high mortality on Bt cotton. However, only a few individuals of the resistant $H$. armigera (BtR) strain could pupate on $\mathrm{Bt}$ cotton, while most BtR individuals could complete their life cycle on artificial diet with a high concentration of Cry1Ac protoxin $(50 \mu \mathrm{g} / \mathrm{g})$ (Liang et al., unpubl. data). Reasons for this observed difference may include interactions between plant chemistry and $\mathrm{Bt}$ toxins or nutritional benefits from the artificial diet.

In northern China, the cotton bollworm passes through the cold winter as a diapause pupae. It has been suggested that the overwintering limit for cotton bollworm is $-15^{\circ} \mathrm{C}$ for the mean low temperature in January ( $\mathrm{Wu}$ et al., 1997b). Changes to the diapause inducement condition and cold hardiness should affect the overwintering survival percentage of $H$. armigera. Flight ability directly affects the $H$. armigera moth mating percentage and gene exchange in the field. Although Bt-cotton resistance has not become a problem in China (Wu \& Guo, 2005), more research on Bt-resistance management is needed. 
The results of the current study give insight into physiological and life-cycle changes in $H$. armigera associated with $\mathrm{Bt}$ resistance. We hope that these results will contribute to the further establishment of efficacious Btresistance management strategies in China and other countries where $H$. armigera are exposed to Bt crops.

ACKNOWLEDGEMENTS. We thank Dr. Tingchang Zhao (IPP, CAAS) for assisting to determine the cold hardiness and Dr. Xingfu Jiang (IPP, CAAS) for measuring the flight ability. We also thank Professor Tongxian Liu (Texas Agricultural Experiment Station, Texas A \& M University) for reviewing this paper. This research was supported by the grant (No. 30200182) from the National Natural Science Foundation of China, and the grant ( No. 2006CB102004) from the Ministry of Science and Technology of China.

\section{REFERENCES}

Akhurst R.J., James W., BiRd L.J. \& Beard C.E. 2003: Resistance to the Cry1Ac $\delta$-endotoxin of Bacillus thuringiensis in the cotton bollworm, Helicoverpa armigera (Lepidoptera: Noctuidae). J. Econ. Entomol. 96: 1290-1299.

AlyoKhin A.V. \& Ferro D.N. 1999: Relative fitness of colorado potato beetle (Coleoptera: Chrysomelidae) resistant and susceptible to the Bacillus thuringiensis Cry3A toxin. J. Econ. Entomol. 92: 510-515.

Bates S.L., Zhao J.Z., Roush R.T. \& Shelton A.M. 2005: Insect resistance management in GM crops: past, present and future. Nat. Biotechnol. 23: 57-62.

Beerwinkle K.R., Lopez J.D. JR., Cheng D., Lingeren P.D. \& Meola R.W. 1995: Flight potential of feral Helicoverpa zea (Lepidoptera: Noctuidae) males measured with 32-channel, computer-monitored, flight-mill system. Environ. Entomol. 24: $1122-1130$.

BIRD L.J. \& AkhURst R.J. 2004: Relative fitness of Cry1Aresistant and -susceptible Helicoverpa armigera (Lepidoptera: Noctuidae) on conventional and transgenic cotton. J. Econ. Entomol. 97: 1699-1709.

BIRD L.J. \& AKhURST R.J. 2005: Fitness of Cry1A-resistant and -susceptible Helicoverpa armigera (Lepidoptera: Noctuidae) on transgenic cotton with reduced levels of Cry1Ac. J. Econ. Entomol. 98: 1311-1319.

CAPrio M.A., FAVER M.K. \& Hankins G. 2004: Evaluating the impacts of refuge width on source-sink dynamics between transgenic and non-transgenic cotton. J. Insect Sci. 4: 1-5.

CARRIĖRE Y. \& RofF D.A. 1995: The joint evolution of diapause and insecticide resistance: a test of an optimality model. Ecology. 76: 1497-1505.

Carrière Y., Ellers-Kirk C., Patin A.L., Sims M.A., Meyer S., Liu Y.B., Dennehy T.J. \& Tabashnik B.E. 2001: Overwintering cost associated with resistance to transgenic cotton in the Pink bollworm (Lepidoptera: Gelechiidae). J. Econ. Entomol. 94: 935-941.

Eger J.E., Witz J.A. Jr., Hartstack A.W. Jr. \& Sterling W.L. 1982: Survival of pupae of Heliothis virescens and Heliothis zea (Lepidoptera: Noctuidae) at low temperatures. Can. Entomol. 114: 289-301.

Forrester N.W., Cahill M., Bird L.J. \& Layland J.K. 1993 Management of pyrethroid and endosulfan resistance in Helicoverpa armigera (Lepidoptera: Noctuidae) in Australia. Bull. Entomol. Res. (Suppl. No. 1): 132 pp.

Gahan L.J., Ma Y.-T., Coble M.L.M., Gould F., Moar W.J. \& Heckel D.G. 2005: Genetic basis of resistance to Cry1Ac and Cry2Aa in Heliothis virescens (Lepidoptera: Noctuidae). $J$. Econ. Entomol. 98: 1357-1368.
Groeters F.R., Tabashnik B.E., Finson N. \& Johnson M.W. 1994: Fitness cost of resistance to Bacillus thuringiensis in the diamondback moth (Plutella xylostella). Evolution 48: 197-201.

Guo Y.Y. 1997: Progress in the researches on migration regularity of Helicoverpa armigera and relationships between the pest and its host plants. Acta Entomol. Sin. 40: 1-6.

Higginson D.M., Morin S., Nyboer M.E., Biggs R.W., TABASHNIK B.E. \& CARRIÈre Y. 2005: Evolutionary trade-offs of insect resistance to Bacillus thuringiensis crops: fitness cost affecting paternity. Evolution 59: 915-920.

Hu Z.D., Li X.C. \& WANG Y.C. 1999: A comparative study on diapause of Helicoverpa armigera (Hübner) with different fenvalerate resistance levels. Entomol. Knowl. 36: 270-272.

HuAng F.N., Buschman L.L. \& Higgins R.A. 2005: Larval survival and development of susceptible and resistant Ostrinia nubilalis (Lepidoptera: Pyralidae) on diet containing Bacillus thuringiensis. Agri. Forest Entomol. 7: 45-52.

Kranthi K.R., Kranthi S., Ali S. \& Banerjee S.K. 2000: Resistance to CrylAc $\delta$-endotoxin of Bacillus thuringiensis in a laboratory selected strain of Helicoverpa armigera (Hübner). Curr. Sci. 78: 1001-1004.

Liang G.M., Tan W.J. \& Guo Y.Y. 1999: An improvement in the technique of artificial raring cotton bollworm. Plant Prot. 25: $15-17$.

Liang G.M., Tan W.J. \& Guo Y.Y. 2000: Studies on the resistance screening and cross-resistance of cotton bollworm to Bacillus thuringiensis (Berliner). Sci. Agri. Sin. 33: 46-53.

LiU Y.B. \& TABASHNIK B.E. 1997: Experimental evidence that refuges delay insect adaptation to Bacillus thuringiensis. Proc. R. Soc. London (Ser. B) 264: 605-610.

Luttrell R.G., Fitt G.P., Ramalho F.S. \& Sugonyaev E.S. 1994: Cotton pest management: Part 1. A worldwide perspective. Annu. Rev. Entomol. 39: 517-526.

Peck S., Gould F. \& Ellner S.P. 1999: Spread of resistance in spatially extended regions of transgenic cotton: implications for management of Heliothis virescens (Lepidoptera: Noctuidae). J. Econ. Entomol. 92: 1-6.

Phillips J.R. \& Newsom L.D. 1966: Diapause in Heliothis zea and Heliothis virescens (Lepidoptera: Noctuidae). Ann. Entomol. Soc. Am. 59: 154-159.

Ramachandran S., Buntin G.D., All J.N., Tabashnik B.E., Raymer P.L., Adang M.J., Pulliam D.A. \& Stewart C.N. JR. 1998: Survival, development, and oviposition of resistant diamondback moth (Lepidoptera: Plutellidae) on transgenic canola producing a Bacillus thuringiensis toxin. J. Econ. Entomol. 91: 1239-1244.

Russell R.M., Robertson J.L. \& SAVIN N.E. 1977: POLO: a new computer program for probit analysis. Rev. Entomol. Soc. Am. 23: 209-215.

SAS Institute 1996: SAS/STAT User's Guide, Version 6.0. SAS Institute, Cary, NC.

Shelton A.M., Tang J.D., Roush R.T., Metz T.D. \& Earle E.D. 2000: Field tests on managing resistance to Bt-engineered plants. Nature Biotechnol. 18: 339-342.

Shelton A.M., Zhao J.Z. \& Roush R.T. 2002: Economic, ecological, food safety, and social consequences of the deployment of Bt transgenic plants. Annu. Rev. Entomol. 47: 845-881.

TABASHNIK B.E. 1994: Evolution of resistance to Bacillus thuringiensis. Annu. Rev. Entomol. 39: 47-79.

TABAShNIK B.E. \& CARRIÈRE Y. 2004: Bt transgenic crops do not have favorable effects on resistant insects. J. Insect Sci. 4: $1-3$. 
Tabashnik B.E., Carrière Y., Dennehy T.J., Morin S., SisTerson M.S., Roush R.T., Shelton A.M. \& Zhao J.Z. 2003: Insect resistance to transgenic Bt crops: lessons from the laboratory and field. J. Econ. Entomol. 96: 1031-1038.

TABASHNIK B.E., Gould F. \& CARRIÈre Y. 2004: Delaying evolution of insect resistance to transgenic crops by decreasing dominance and heritability. J. Evol. Biol. 17: 904-912.

Tabashnik B.E., Biggs R.W., Higginson D.M., Henderson S., Unnithan D.C., Unnithan G.C., Ellers-Kirk C., Sisterson M.S., Dennehy T.J., Carrière Y. \& Morin S. 2005: Association between resistance to Bt cotton and cadherin genotype in pink bollworm. J. Econ. Entomol. 98: 635-644.

Tang J.D., Gilboa S., Roush R.T. \& Shelton A.M. 1997: Inheritance, stability, and lack of fitness cost of field-selected resistance to Bacillus thuringiensis in diamondback moth (Lepidoptera: Plutellidae) from Florida. J. Econ. Entomol. 90: 732-741.
Tang J.D., Collins H.L., Metz T.D., Earle E.D., Zhao J.Z., Roush R.T. \& Shelton A.M. 2001: Greenhouse tests on resistance management of $\mathrm{Bt}$ transgenic plants using refuge strategies. J. Econ. Entomol. 94: 240-247.

Wu K.M. \& Guo Y.Y. 1995: Inducing factors of pupal diapause in Helicoverpa armigera. Acta Phytophyl. Sin. 22: 331-336.

Wu K.M. \& Guo Y.Y. 2005: The evolution of cotton pest management practics in China. Annu. Rev. Entomol. 50: 31-52.

Wu K.M., Liang G.M. \& Guo Y.Y. 1997a: Phoxim resistance in Helicoverpa armigera (Lepidoptera: Noctuidae) in China. $J$. Econ. Entomol. 90: 868-872.

Wu K.M., Guo Y.Y., Wei J.F. \& Sun F.Z. 1997b: On the cold hardiness of cotton bollworm, Helicoverpa armigera (Hübner). Acta Ecol. Sin. 17: 298-302.

Zhu H., Sun F.Z., Zhang Y.X. \& Wang W.L. 1994: The effects of INA bacteria on the freezing temperature of cotton bollworm. Sci. Agri. Sci. 27: 23-27.

Received January 31, 2007; revised and accepted August 13, 2007 